Artigo Original

\title{
Fatores geradores de estresse para atletas da categoria de base do futebol de campo
}

\author{
Priscilla Bertoldo dos Santos \\ Ricardo Weigert Coelho \\ Birgit Keller \\ Joice Mara Facco Stefanello \\ Laboratório de Pesquisa em Psicofisiologia do Exercício e Esporte,
Universidade Federal do Paraná, Curitiba, PR, Brasil
}

Resumo: O objetivo deste estudo foi verificar a intensidade e direcionalidade das situações geradoras de estresse para atletas da categoria de base de futebol de campo em diferentes estágios maturacionais. Participaram 18 atletas, do sexo masculino, com idade média de 16,6 $( \pm 0,5)$ anos. Para a coleta de dados foi utilizado o Inventário dos Fatores de Stress no Futebol (ISF) e a avaliação do estágio maturacional através da idade esquelética. Os atletas foram divididos em dois grupos, maturação normal e precoce. Os resultados dos índices de direcionalidade e intensidade da percepção dos fatores geradores de estresse evidenciaram que não houve diferença significativa entre os grupos de diferentes níveis maturacionais. Entretanto, entre os fatores geradores de estresse, foi verificada diferença significativa entre os grupos para três fatores: "grande superioridade dos adversários"; "jogar com muito calor"; "pressão do técnico para vencer".

Palavras-chave: estresse; maturação; futebol; categoria de base.

\section{Stress factors for soccer athletes of basic category}

\begin{abstract}
The purpose of this study was to analyze the intensity and directionality of situations that cause stress in soccer players in a beginners' category at different maturation stages. The study included 18 male soccer players, mean age of $16.6( \pm 0.5)$ years. We used the Stress Factors in Soccer Inventory (ISF) and further assessed the pubertal stage based on skeletal age. Players were separated in two groups, early and normal maturation age. The results of intensity and directionality index of perception of stress generating factors did not differ between the maturation groups. However, differences between the two groups appeared in three factors causing stress: "great superiority of their opponents," "play with a lot of heat"; "technical pressure to win".
\end{abstract}

Keywords: stress; maturation; soccer; basic category.

\section{Introdução}

No contexto esportivo, os atletas estão constantemente sujeitos aos mais diversos tipos de pressão, tanto externas (avaliação do desempenho pelos técnicos e demais participantes, expectativas do treinador em relação ao desempenho do atleta, comportamento da torcida e as críticas dos companheiros de equipe), como internas (alcance de objetivos pessoais, as expectativas de sucesso ou fracasso e as percepções dos atletas sobre vitórias e derrotas) (DE ROSE JR, 1997). Dependendo da percepção individual do atleta, pressão interna e pressão externa podem se transformar em fatores geradores de estresse. Ou seja, determinada situação poderá ser considerada um fator gerador de estresse para certo, mas não a outros. Isso porque a percepção do estresse depende da avaliação da demanda, da qualidade de recursos e da experiência que o indivíduo dispõe para lidar com cada situação (STEFANELLO, 2007).

A forma como o indivíduo avalia as situações ou os estímulos é, portanto, o que determina o modo como ele irá responder a uma situação estressora e como será afetado pelo estresse (MARGIS et al., 2003). Como a percepção que o atleta tem de uma dada situação, determina o estresse potencial vivenciado pelo atleta e sua consequente reposta emocional e comportamental, a resposta do indivíduo a um estímulo estressor pode ser tanto negativa (ameaça, preocupação e/ou medo) como positiva (desafiadora e/ou motivante) (DE ROSE JR, 1999).

Tradicionalmente, o termo estresse é entendido como uma reação negativa que pode prejudicar a atuação dos atletas. De fato, algumas situações esportivas causam ou produzem 
sintomas físicos (aumento do batimento cardíaco, sudorese, respiração ofegante, músculos tensos, boca seca), mentais (medo, ansiedade, inabilidade para se concentrar, dificuldade para tomar decisões, perda do controle) e comportamentais (maneirismos nervosos), que dificultam a obtenção de um bom desempenho do atleta. Entretanto, o estresse pode ser percebido como algo positivo, preparando o corpo para a atividade explosiva e deixando o indivíduo alerta (estimulando-o fisiologicamente, ajudando-o a manter o foco de atenção, a motivação, o entusiasmo e a conservar um alto nível de energia física). Em outras palavras, preparando o organismo do atleta para um ótimo desempenho (BRANDÃO, 2000; LIPP, 2003).

Assim, a capacidade para lidar com o estresse pode ser determinante para o rendimento de um atleta (DE ROSE et al., 2004; KORUC et al., 2007; PAIN; HARWOOD, 2007; STEFANELLO, 2007). No futebol, por exemplo, assim como em outras modalidades esportivas, existe uma grande preocupação em relação à queda de produção do jogador nos treinamentos e nas partidas, o que compromete a continuidade e a escalação do jogador para os próximos jogos. Para atender o que se espera dele, o jogador precisa enfrentar adequadamente as expectativas do treinador, de seus companheiros de equipe, dos seus familiares, dos amigos e dos meios de comunicação (BRANDÃO, 2000). Considerando que os atletas mais jovens se encontram em fases sensíveis de desenvolvimento da sua personalidade, estes poderão apresentar maiores dificuldades em controlar suas reações emocionais (SAMULSKI; CHAGAS, 1992). Em atletas entre 16 e 17 anos, o estresse se manifesta tanto em nível físico como psicológico, e sua expressão pode variar de leve a muito intensa (STERLEMANN; GANEA et al., 2007).

Um estudo realizado por De Rose et al. (2004) com 417 atletas de basquetebol, handebol e voleibol, com idade média de 16,3 anos, apontou que as situações que mais causam estresse para os jovens atletas durante o jogo, nas três modalidades investigadas, foram "errar em momentos decisivos"; "repetir os mesmo erros"; "perder jogo praticamente ganho" e "arbitragem prejudicial ao atleta ou à sua equipe". Weinberg e Gold (2001) defendem que a preocupação excessiva com a profissionalização, em garantir um futuro promissor, e com a ideia distorcida de que as categorias de base precisam gerar tanto lucro como a categoria profissional - tratando os jovens esportistas como "mini-profissionais", desconsiderando as transformações decorrentes da própria fase de vida -, contribuem significativamente para o aparecimento dos inúmeros fatores geradores de estresse nesses indivíduos.

É preciso ressaltar que, durante a adolescência, os jovens esportistas passam por alterações em diversos níveis (físico, mental e social) e por um processo de aquisição de características e competências que os capacitem a assumir os deveres e os papéis sociais de um adulto (SAMULSKI, 2002; STEINBERG, 1993). Por outro lado, sua maturação biológica não ocorre, necessariamente, em sincronia com a idade cronológica, de modo que as possíveis diferenças apresentadas entre indivíduos do mesmo sexo podem refletir-se em diferentes graus de maturidade biológica e possivelmente diferentes respostas às situações estressoras (MALINA; BOUCHARD, 2002; TOURINHO FILHO; TOURINHO, 1998).

Alguns estudos (VILLAR; DENADAI, 2001; MIRWALD, 2002; MAZZUCO, 2007) têm demonstrado que, quando comparadas idades biológicas, as diferenças entre grupos de indivíduos da mesma idade cronológica resultam em diferentes estágios do desenvolvimento biológico das diversas funções e condições do organismo. Nesse sentido, através da comparação entre a idade cronológica e a idade biológica dos indivíduos podem-se encontrar atletas com estágio de maturação tardio, normal ou precoce (FREITAS et al., 2003).

Nesse sentido, apesar de o treino e a atividade física regular serem geralmente interpretados como exercendo uma influência favorável no crescimento, na maturação e na aptidão física da criança e do jovem (MALINA, 1997), a presença de atletas no estágio maturacional tardio é rara devido ao processo de seleção para o esporte. Os atletas são um grupo altamente selecionado, tomando por base, geralmente, as suas habilidades e, em alguns desportos, a estatura dos sujeitos (SEABRA et al., 2001).

Dados obtidos em estudo de Malina et al. (2000) com atletas de futebol mostraram que até aproximadamente 13 anos de idade, há uma distribuição de jogadores com idade biológica (IB) e idade cronológica (IC) equilibrada, assim como semelhante incidência de jogadores que apresentam um estágio maturacional tardio. Já 
em faixas etárias maiores que 13 anos, torna-se evidente o maior número de jogadores situados na faixa superior da linha da maturação precoce. O pequeno número de jogadores no estágio maturacional tardio é, possivelmente, reflexo da exclusão de jogadores com menor desenvolvimento físico já nas primeiras fases da carreira profissional. Na medida em que os jogadores passam para uma categoria superior no futebol (por exemplo, do infantil para o juvenil), ocorre uma seleção natural do grupo de jogadores que continuam na equipe. Como ainda não existem muitos critérios e/ou referenciais bem estabelecidos para determinar se um jogador será ou não bem-sucedido ao longo de sua carreira até atingir o nível profissional, a maioria dos jogadores são selecionados com base no maior porte físico e maior força muscular, dentre outras valências que primam 0 aspecto físico de cada um deles (MALINA et al., 2004). Penã Reyes et al. (1994) ) também demonstraram em seus estudos que existe uma grande incidência de jovens jogadores de futebol no estágio maturacional acelerado.

A maturação biológica pode ser determinada através das idades óssea, neural, dental, morfológica, somática e sexual. Cada qual apresenta vantagens e desvantagens metodológicas, sendo que as mais utilizadas são a idade esquelética e a avaliação através do desenvolvimento dos caracteres sexuais secundários (ROBERGS; ROBERTS, 1997; OLIVEIRA et al., 2000).

Com base nesses argumentos e considerando os poucos trabalhos publicados no Brasil sobre estresse no futebol (SANCHES, 2004), o objetivo do presente estudo foi verificar a intensidade $e$ direcionalidade das situações geradoras de estresse para atletas da categoria de base de futebol de campo em diferentes estágios maturacionais.

\section{Metodologia}

Este estudo inclui um delineamento transversal e descritivo e foi aprovado pelo
Comitê de Ética em Pesquisa do Setor de Ciências da Saúde da UFPR (registro 948.073.10.6 e CAEE 2599.0.000.091-10), conforme estabelece a Resolução CNS 196/96.

Participaram deste estudo 18 atletas da categoria de base de futebol de campo, do sexo masculino, com idade média de 16,6 $( \pm 0,5)$ anos e 8,3 $( \pm 2,1)$ anos de prática na modalidade.

Antes de iniciar a coleta de dados, foi solicitada a autorização do clube e a autorização dos responsáveis pelos atletas, que assinaram o Termo de Consentimento Livre e Esclarecido, sendo mantido o anonimato dos participantes.

Para a coleta de dados foram utilizados dois instrumentos, o Inventário dos Fatores de Stress no Futebol (ISF) e a avaliação do estágio maturacional através da idade esquelética.

O Inventário dos Fatores de Stress no Futebol (ISF), proposto e validado por Brandão (2000), foi utilizado para identificar a direcionalidade e a intensidade da percepção dos fatores geradores de estresse para atletas de futebol. A precisão do instrumento foi analisada por meio da análise fatorial Varimax e do coeficiente alpha de Cronbach. A construção dos itens que compõe o instrumento foi baseada em uma revisão histórica do estresse no esporte, especificamente em testes desenvolvidos por alguns pesquisadores para avaliar estresse no futebol (FRESTER, 1976; SAMULSKI; CHAGAS, 1992; TEIPEL, 1993 citados por BRANDÃO, 2000). Os itens foram formulados com a linguagem típica do futebol, tal como caneta (quando uma bola passa entre as pernas de um jogador), chapéu (quando um jogador dribla seu adversário, passando a bola sobre sua cabeça) e morte súbita (quando um jogo termina assim que um dos times faz um gol). O inventário foi elaborado de forma que os 77 itens ficassem agrupados e representassem 7 grandes fontes de estresse, cada uma formada por alguns itens do questionário, os quais podem ser observados no Quadro 1.

Quadro 1. Fontes de estresse do ISF

\begin{tabular}{|c|l|c|}
\hline & \multicolumn{1}{|c|}{ FONTES DE ESTRESSE } & ITENS \\
\hline $\mathbf{1}$ & Situações de fracasso eminente ou real & $4,11,12,15,23,27,29,30,33,35,36,37,38,56,57,63,64,65,70$ e 72 \\
\hline $\mathbf{2}$ & Situações de aspectos da competição & $7,19,21,25,39,44,45,51,52,58,60,76$ \\
\hline $\mathbf{3}$ & Situações de demanda física e psicológica & $26,31,32,34,42,43,48,55,68,69$ \\
\hline $\mathbf{4}$ & Situações de conflito & $3,6,8,9,10,14,17,18,24$ \\
\hline $\mathbf{5}$ & Situações de perturbação & $50,59,61,66,67,73,74,75,77$ \\
\hline $\mathbf{6}$ & Situações de risco físico & $5,20,28,41,47,49,62,71$ \\
\hline $\mathbf{7}$ & Situações de crítica e repreensão & $1,2,13,22,46,53,54$ \\
\hline
\end{tabular}


Os itens são avaliados por uma escala com 7 posicionamentos relacionados aos fatores de estresse $(-3=$ muito negativo; $-2=$ mais ou menos negativo; $-1=$ pouco negativo; $0=$ neutro; $+1=$ pouco positivo; $+2=$ mais ou menos positivo; $+3=$ muito positivo). $O$ instrumento indica a direcionalidade (se o estresse é positivo, neutro ou negativo) e a intensidade (de muito negativo até muito positivo) da reação do atleta a uma determinada situação estressora. Assim, apresenta grandes implicações práticas em termos de estratégias de intervenção no futebol, que podem ajudar os jogadores a enfrentar as situações estressoras que fazem parte do dia-adia.

Após o termino de uma competição, em uma sala reservada pela pesquisadora, o ISF foi aplicado aos atletas uma única vez obedecendo as orientações sobre o preenchimento do mesmo.

A avaliação do estágio maturacional dos atletas incluiu a idade esquelética a partir da radiografia das mãos e dos punhos dos atletas, seguindo o método proposto por Greulich e Pyle (1959). O método Greulich-Pyle também chamado de "Método Atlas", realiza a comparação da radiografia mão-punho de uma criança específica com radiografias-padrão correspondentes a níveis sucessivos de maturação esquelética em idades cronológicas específicas. A comparação óssea individual, ou seja, idade esquelética, inclui a média das idades esqueléticas de cada osso. Para isso, todos os 30 ossos da mão são utilizados. Para a adequação da idade cronológica dos atletas ao seu estágio maturacional foi utilizado o cálculo da diferença entre a idade esquelética e a idade cronológica (IE-IC). Atletas com resultados entre $-1,00$ e $+1,00$ na idade esquelética foram considerados com estágio maturacional normal. Atletas com resultados menores que $-1,00$ foram enquadrados no grupo maturacional tardio. Se 0 atleta apresentou resultado maior que $+1,00$, foi classificado como tendo estágio maturacional precoce (FREITAS et al., 2003; MAZZUCO, 2007). A partir desta distribuição, obtivemos dois grupos para a amostra estudada: atletas com estágio maturacional normal e precoce. A avaliação da maturação biológica através das informações relativas à maturação esquelética provavelmente é a mais indicada em estudos que envolvem crianças e adolescentes, já que pode ser aplicada como medida avaliativa desde 0 nascimento até por volta dos 17-18 anos de idade. $O$ desenvolvimento esquelético segue sempre a mesma ordem maturacional, sua ossificação ocorre no sentido próximo-distal e não varia em crianças doentes, mal nutridas ou por razões étnicas, sendo, portanto, de validade universal (ERAGOSO; VIEIRA, 1999).

Avaliações considerando a idade esquelética têm sido adotadas para identificar o padrão maturacional de jovens desportistas (MATSUDO; MATSUDO, 1995; BEUNEN et al., 1997; TOURINHO FILHO; TOURINHO, 1998), inclusive de futebolistas (PENÃ REYES et al., 1994; MALINA et al., 2000).

As radiografias foram realizadas no Centro de Diagnóstico Radiológico e por Imagens Dr. Guido Pérez - CDI. O equipamento utilizado para a radiografia foi o aparelho VMI Compacto 500 e o tempo de exposição dos atletas ao raio $X$ foi de 0,10 segundos. Para a radiografia, ambas as mãos foram posicionadas sob o chassi do aparelho em posição postero-anterior, com a precaução de não omitir as falanges e a articulação do punho. As radiografias foram realizadas por uma equipe especializada do Centro de Diagnóstico Radiológico e Imagens Dr. Guido Pérez - $\mathrm{CDI}$, home page: www.cdipr.com.br, tendo como médico responsável o Dr. Carlo Alessandro Martins Villavicencio (CRM: 16477).

A análise estatística foi realizada com 0 auxílio do programa estatístico SPSS versão 18.0. A normalidade dos dados para todas as variáveis estudadas foi confirmada pelo teste de Kolmogorov-Smirnov.

$\mathrm{Na}$ descrição das variáveis foram empregados os procedimentos descritivos de média e desvio padrão. $\mathrm{Na}$ estatística inferencial foi empregada uma ANOVA para verificar a diferença entre os grupos, tanto dos fatores como das fontes do estresse, considerando um nível significativo de $p \leq 0,05$.

\section{Resultados}

Os atletas foram divididos em dois grupos de acordo com o seu estágio maturacional. Dessa forma, 10 atletas compuseram o grupo com maturação precoce e 8 o grupo com maturação normal. Nenhum atleta participante apresentou maturação tardia. Considerando o grupo como um todo, independente do estágio maturacional dos atletas, os valores descritivos das fontes de estresse do ISF são apresentados na Tabela 1. 
Tabela 1. Valores descritivos das fontes de estresse.

\begin{tabular}{lcccc}
\hline \multicolumn{1}{c}{ Maturação } & \multicolumn{2}{c}{ Precoce } & \multicolumn{2}{c}{ Normal } \\
\hline Fontes & Média & d.p. & Média & d.p. \\
1 Situações de fracasso eminente ou real & $-1,23$ & 0,33 & $-1,51$ & 0,34 \\
2 Situações de aspectos da competição & 1,09 & 0,47 & 1,08 & 0,22 \\
3 Situações de demanda física e psicológica & 0,61 & 0,44 & 0,26 & 0,28 \\
4 Situações de conflito & $-0,22$ & 0,34 & $-0,92$ & 0,38 \\
5 Situações de perturbação & $-1,42$ & 0,16 & $-1,63$ & 0,52 \\
6 Situações de risco físico & 0,39 & 0,54 & 0,20 & 0,28 \\
7 Situações de crítica e repreensão & $-0,95$ & 0,24 & $-1,30$ & 0,43 \\
\hline
\end{tabular}

Quando analisada a diferença das fontes de estresse entre os dois grupos de atletas, considerando o seu estágio maturacional, observou-se que não houve diferença significativa em nenhuma das fontes entre os grupos com maturação precoce e normal, conforme Tabela 2.

Tabela 2. Diferenças das fontes de estresse entre os grupos com maturação precoce e normal.

\begin{tabular}{lccccc}
\hline \multicolumn{1}{c}{ Fontes } & $\begin{array}{c}\text { Soma dos } \\
\text { Quadrados }\end{array}$ & GL & $\begin{array}{c}\text { Média dos } \\
\text { Quadrados }\end{array}$ & F & p \\
\hline 1 Situações de fracasso eminente ou real & 0,648 & 1 & 0,648 & 1,214 & 0,277 \\
2 Situações de aspectos da competição & 0,001 & 1 & 0,001 & 0,001 & 0,975 \\
3 Situações de demanda física e psicológica & 0,623 & 1 & 0,623 & 0,431 & 0,520 \\
4 Situações de conflito & 2,198 & 1 & 2,198 & 1,108 & 0,308 \\
5 Situações de perturbação & 0,160 & 1 & 1,160 & 0,238 & 0,633 \\
6 Situações de risco físico & 0,145 & 1 & 0,145 & 0,054 & 0,820 \\
7 Situações de crítica e repreensão & 0,438 & 1 & 0,438 & 0,432 & 0,524 \\
\hline
\end{tabular}

Como cada fonte é composta por vários fatores (Quadro 1), quando verificada a diferença entre os grupos para cada fator, encontraram-se diferenças significativas em 3 fatores $(p \leq 0,05)$, que são apresentados na Tabela 3.
A Figura 1 demonstra a direcionalidade (positivo, neutro ou negativo) e a intensidade (de muito negativo até muito positivo) dos fatores geradores de estresse que apresentaram significância estatística para os atletas com maturação normal e precoce.

Tabela 3. Diferença dos fatores geradores de estresse entre os grupos com maturação precoce e tardia.

\begin{tabular}{lccccc}
\hline \multicolumn{1}{c}{ Fatores } & $\begin{array}{c}\text { Soma dos } \\
\text { Quadrados }\end{array}$ & GL & $\begin{array}{c}\text { Média dos } \\
\text { Quadrados }\end{array}$ & F & p \\
\hline 14 Grande superioridade dos adversário & 10,336 & 1 & 10,336 & 5,288 & 0,035 \\
51 Pressão do técnico para vencer & 8,711 & 1 & 8,711 & 4,908 & 0,042 \\
71 Jogar com muito calor & 10,678 & 1 & 10,678 & 4,605 & 0,048 \\
\hline
\end{tabular}

Figura 1. Direcionalidade e intensidade dos fatores geradores de estresse.

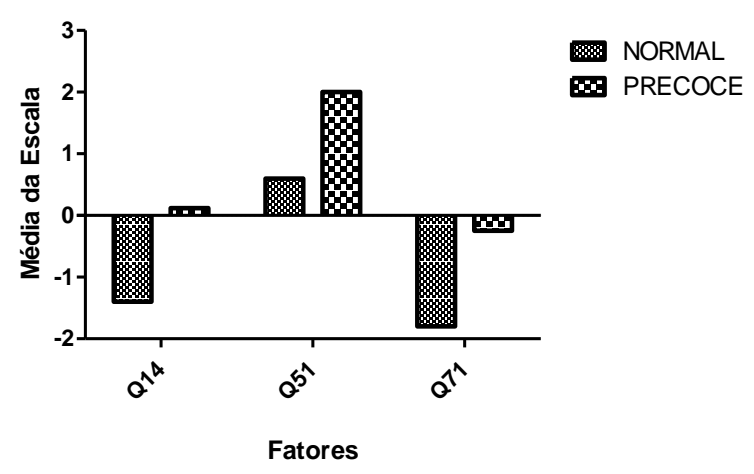

Quanto à direcionalidade e intensidade do estresse, os atletas com maturação normal avaliaram os fatores "grande superioridade dos adversários" (Q14) e "jogar com muito calor" (Q71) como aspectos negativos e com intensidade moderada de estresse (entre -1,40 e 1,80 ), pois corresponderam a fatores negativos que foram mais ou menos estressantes para os atletas. O fator "pressão do técnico para vencer" (Q51) para esse grupo de esportistas foi considerado positivo, embora com baixa intensidade $(0,60)$

Para o grupo com maturação precoce, o único fator considerado negativo foi "jogar com muito calor" (Q71), embora tenha apresentado baixa 
intensidade $(-0,25)$. Por outro lado, os fatores "pressão do técnico para vencer" (Q51) e "grande superioridade dos adversários" (Q14) foram fatores avaliados positivamente pelos atletas, diferindo apenas na sua intensidade. Ou seja, enquanto a pressão do técnico exerce forte influência sobre os atletas (2,00), a grande superioridade dos adversários não parece ser muito relevante $(0,12)$.

\section{Discussão}

$\mathrm{Na}$ atualidade, o futebol é visto como um fenômeno social abrangente, tanto no aspecto do espetáculo, como de atividade profissional e comercial, atingindo, direta ou indiretamente, toda a população brasileira. Por fazer parte da identidade do país e ser considerado como uma paixão nacional, o futebol é visto como uma oportunidade de ascensão social e profissional para adolescentes (RUBIO, 2006; MARQUES; SAMULSKI, 2009). Esses, seduzidos por uma vida social de status e independência financeira e incentivados por seus pais, visualizam a carreira de jogador de futebol como uma das mais promissoras, procurando as categorias de base para uma formação profissional. Esta expectativa é influenciada ainda mais pela mídia esportiva, que enfatiza principalmente o lado "positivo" da profissão, destacando o sucesso de alguns dos principais jogadores brasileiros (AMARAL et al., 2007). Nesse sentido, muitos adolescentes transformam o futebol em um grande sonho de realização profissional. Porém, esta realização depende não só dos pré-requisitos físicos, técnicos, táticos dos atletas, mas também de suas competências emocionais (EKBLOM, 1995).

Smoll e Smith (1989) afirmam que atletas jovens que se encontram em fases sensíveis de desenvolvimento da personalidade podem apresentar problemas no controle de suas emoções e reações dentro de situações competitivas.

Considerando a experiência no esporte como uma condição para enfrentar as situações de estresse em competições, Samulski e Chagas (1992), analisaram o estresse psíquico na competição em jogadores de futebol de campo das categorias infantil e juvenil. Os resultados demonstraram que conflitos com o treinador, companheiros de time e familiares, nervosismo excessivo, dormir mal na noite anterior à competição, e sensação de debilidade física foram consideradas as situações mais estressantes para os jogadores. $O$ que não foi corroborado no presente estudo, pois nenhum desses fatores foi identificado como influenciador de estresse nos dois grupos estudados.

Comparando os fatores estressores entre atletas com menos de 16 anos e mais de 16 anos, Samulski e Chagas (1992) encontraram que os jogadores de mais idade apresentaram uma maior estabilidade emocional e maior resistência ao estresse competitivo. Entretanto, anos mais tarde (1996), os mesmos autores avaliaram o estresse psíquico na competição de jogadores de futebol de campo das categorias juvenil e júnior. Os resultados desse estudo evidenciaram a relação entre estresse psíquico e o futebol, especialmente com jogadores em início de carreira. Porém, não foram encontradas diferenças significativas ao se comparar jogadores das categorias juvenis e juniores. Este resultado corrobora com o presente estudo, realizado com os atletas da categoria de base, pois, de modo geral, não foram encontradas diferenças significativas nas fontes geradoras de estresse entre os atletas com maturação normal ou precoce.

Segundo Jones, Swain e Cale (1990) e Jones e Swain (1995), não basta apenas analisar se determinados fatores geram ou não estresse, mas sim, e principalmente, a percepção "direcional dos sintomas", uma vez que a natureza da interpretação individual dos sintomas pode ser entendida como negativa ou positiva para a performance subsequente. . Para esses autores, os atletas que se percebem capazes de enfrentar a situação estressora e de atingir a meta, tendem a interpretar a situação como facilitadora. Contrariamente, aqueles que percebem a si mesmos como não tendo controle sobre a situação estressora tendem a interpretar a situação como debilitadora do desempenho. Neste sentido, o evento ou a situação estressora é um estímulo que pode ser avaliado tanto negativa quanto positivamente. Dependendo dessa avaliação, a resposta do atleta poderá se constituir em uma reação de estresse negativa, com alterações no sistema nervoso autônomo, desfavoráveis para o rendimento ou em uma reação de coping que produzirá reações positivas para o enfrentamento da situação ( $\underline{\text { SANCHES, }}$ 2004).

No presente estudo não foram observadas diferenças significativas na direcionalidade das 
fontes de estresse para atletas com estágios maturacionais distintos. Ou seja, se uma fonte foi positiva para os atletas com maturação precoce também foi positiva para os atletas com maturação normal. A mesma situação ocorreu com as fontes consideradas negativas. Estes resultados convergem com outros estudos realizados com atletas de futebol das categorias juvenis e juniores (SAMULSKI; CHAGAS, 1996) e com atletas das categorias sub-17 e sub-20 (SANCHES, 2004).

Apesar das diferenças nas fontes geradoras de estresse dos grupos estudados no presente estudo não serem significativas, quando os fatores que compõem 0 instrumento utilizado foram comparados separadamente, observou-se diferenças em três deles. O fator Q14 ("grande superioridade dos adversários") diferiu na direção e intensidade, enquanto os fatores Q51 ("pressão do técnico para vencer") e Q71 ("jogar com muito calor") divergiram apenas na intensidade entre os dois grupos de atletas (com maturação precoce e tardia). A grande superioridade dos adversários, fator que compõe a fonte "situações de conflito", teve direcionalidade contrária do estresse entre os dois grupos, sendo considerada negativa apenas para o grupo com maturação normal e com intensidade moderada no julgamento dos atletas. Isso, possivelmente, se deve ao momento da competição, ou seja, as avaliações foram realizadas no dia do jogo da semifinal, sendo que nessa fase do campeonato permanecem as quatro equipes melhor classificadas. Jogar com muito calor e a pressão do técnico para vencer foram aspectos que diferiram apenas na intensidade entre os dois grupos de atletas. Enquanto jogar com muito calor foi mais estressante para os atletas com maturação normal, a pressão do técnico para vencer foi mais relevante para os atletas com maturação precoce.

Enquanto alguns autores (FIELSTEIN et al., 1985; WEISS; McAULEY; EBBECK; WIESE, 1990) salientam a inexistência de diferenças de percepção e/ou intensidade dos fatores geradores de estresse entre diferentes idades, outros (FRIEZE; SNYDER, 1980), referem-se à existência de uma correlação positiva entre a idade e a percepção destes fatores. Um dos possíveis argumentos para essas diferenças é que os atletas mais experientes avaliam as situações com menor intensidade do que atletas mais jovens (CAMPBELL; JONES, 1997; GALOR, TENEBAUM; SHIMRONY, 1986). Tal fato pôde ser confirmado Sanches (2004), que demonstrou que os atletas amadores e os atletas mais jovens tendem a acompanhar a direcionalidade, positiva ou negativa, da percepção das situações estressoras dos atletas profissionais e de mais idade. O mesmo autor, em estudo realizado com atletas de futebol da categoria sub-17 anos, encontrou que os fatores de maior intensidade percebidos pelos esportistas foram: estabelecimento de metas muito altas; jogar um clássico; saber que será titular com antecedência e ficar concentrado na véspera do jogo. Dentre os fatores com direcionalidade negativa foram apontados: cobrança de jornalista através da imprensa e jogar em posição improvisada. Resultados que divergem daqueles encontrados no presente estudo.

Por outro lado, o fato de os atletas do presente estudo perceberem a "grande superioridade dos adversários" como uma ameaça, pode estar associado com a competência que eles avaliam ter para atingir os propósitos que estabelecem. Segundo Brustad et al. (2001), as pesquisas que estudam os aspectos emocionais dos atletas revelam que os jovens com percepção negativa da sua capacidade para atingir determinada meta ou objetivo tendem a ser jogadores ansiosos. Por outro lado, atletas que avaliam positivamente a sua capacidade e têm apoio social tendem a avaliar as situações ou demandas de forma mais positiva.

No fator "pressão do técnico para vencer" observa-se um estresse positivo. Ommundsen e Roberts et al. (2006) observaram o comportamento de 677 jogadores de futebol com idade de 11 a 14 anos em relação aos pais e técnicos e constataram que o técnico passou a ter fundamental importância no controle dos atletas estressados. De acordo com esses autores, os atletas mais jovens têm maior confiança nos técnicos em relação aos pais quando se trata de assuntos que interferem no seu desempenho esportivo.

O fator "jogar com muito calor" foi considerado um fator negativo para os atletas de futebol do presente estudo. Em estudo realizado com atletas profissionais de vôlei de praia, Stefanello (2007) mostrou que as condições climáticas (vento/frio durante as partidas) também podem ser consideradas fontes geradoras de estresse que interferem na atuação e rendimento dos atletas. Outros autores (NIDEFFER, 1991; SAMULSKI, 2002; VEALEY, 1986; WEINBERG; GOULD, 
2001) também têm referido que variações climáticas, ruídos/estímulos visuais, fadiga, pressão dos adversários e arbitragem levam a desatenção em determinadas modalidades, podendo influenciar nos níveis de ativação e de ansiedade dos atletas e, respectivamente, no desempenho.

Apesar das limitações do presente estudo e da necessidade de outras investigações que confirmem esses achados, pode-se concluir que a identificação dos fatores geradores de estresse que afetam o desempenho esportivo é de fundamental importância na área do futebol. Esses resultados poderão ajudar na conscientização do atleta acerca do seu próprio padrão de comportamento e auxiliá-lo a desenvolver estratégias apropriadas de confronto aos conflitos. Estar mais preparado para as pressões do esporte de rendimento, para as incertezas e para as angústias que interferem no sucesso esportivo, pode contribuir para evitar o abandono precoce do esporte.

\section{Referências}

AMARAL, A. C. S. et al. A cultura do corpo ideal nível de satisfação corporal entre escolares de diferentes faixas etárias - estudo comparativo. HU Revista, Juiz de Fora, v.33, n.2, p.41-45, 2007.

BEUNEN, G. P.; MALINA, R. M.; LEFEVRE, J.; CLAESSENS, A. L.; RENSON, R.; SIMONS, J. Prediction of adult stature and noninvasive assessment of biological maturation. Medicine \& Sciense of Sports \& Exercise, K.U. Leuven, Belgium, v.29, n.2, p.225-230, 1997.

\section{BRANDÃO, M. R. F. Fatores de stress em} jogadores de futebol profissional. Tese de doutorado. Universidade Estadual de Campinas, 2000.

BRUSTAD, J.R; BABKES, M.L. SMITH, A.L. Youth in Sport: psychological considerations. In: Singer RN, Hausenblas HA, Janelle C. Handbook of Sport Psychology. New York, p. 604-635, 2001.

CAMPBELL, E; JONES, G. Pre-competition anxiety and self-confidence in elite and non-elite wheelchair sport participants. Adapted Physical Activity Quarterly, New Jersey, v.14, p.95-107, 1997.

DE ROSE JR, D. Sintomas de "stress" no esporte infanto-juvenil. Revista Treinamento Desportivo, Curitiba, v.2, n.3, p.12-20, 1997.

DE ROSE JR, D.; DESCHAMPS, S.; KORKASAS, $P$. Situações causadoras de "stress" no basquetebol de alto rendimento: fatores competitivos. Revista Paulista de Educação Física, São Paulo, v.13, p.2, p.217-229, 1999.

DE ROSE JR, D.; SATO, T. C.; SELINGARDI, D.; BETTENCOURT, E. L.; BARROS, J. C. T. S.; FERREIRA, M. C. M. Situações de jogo como fonte de "stress" em modalidades esportivas coletivas. Revista Brasileira Educação Física e Esporte, São Paulo, v.18, n.4, p.385-395, 2004.

FRAGOSO, M.I; VIEIRA,F. Antropometria aplicada. Actas do 1ํㅡㄹ Ciclo de Conferências. Lisboa: FMH edições, 1999.

EKBLOM, B. Football (Soccer). Londres: Blackwell Scientific Publication, 1995.

FIELSTEIN, E.; KLEIN, M.S.; FISHER, M.; HANAN, C.; KOBURGER, P.; SCHNEIDER, M.J. \& LEITENBERG (1985). Self-esteem and causal attribution for success and failure in children. Cognitive Therapy and Research, New York, v.9(4):381-398, 1985.

FRESTER, R. El "test" del sintoma de carga: un procedimiento para el analisis de la elaboración de condiciones de carga psíquica em los deportista. In Kunath, P. (Org.). Aportes a la Psicologia Deportiva. Editora Orbe, Havana, 1976.

FREITAS, D. L.; MAIA, J. A.; BEUNEN, G. P.; LEFEVRE, J. A.; CLAESSENS, A. L.; MARQUES, A. T.; RODRIGUES, A. L.; SILVA, C. A.; CRESPO, M. T.; THOMIS, M. A.; PHILIPPAERTS, R. M. Maturação esquelética e aptidão física em crianças e adolescentes madeirenses. Revista Portuguesa de Ciências do Desporto, Porto, v.3, n.1, p.61-75, 2003.

FRIEZE, I.H; SNYDER, H.N. Children's beliefs about the causes of success and failure in school settings. Journal of Educational Psychology, Washingotn, v.72(2), p.186-196, 1980.

GAL-OR, Y.; TENENBAUM, G. \& SHIMRONY, S. (1986). Cognitive behavioral strategies and anxiety in elite orienteers. Journal of Sport Sciences.Spring ;4(1),p.39-48,1986.

GREULICH, W. W.; PYLE, S. I. Radiographic Atlas of Skeletal Development of Hand and Wrist. 2nd ed. Stanford: Stanford University Press; 1959.

JONES G.; SWAIN, A.; CALE, A. Antecedents of multidimensional competitive state anxiety and self-confidence in elite intercollegiate middledistance runners. The Sports Psychologist, Birmingham, 4, 1990. 
JONES, G.; SWAIN, A. B. J. Predispositions To Experience Debilitative and Facilitative Anxiety in Elite and Nonelite Performers. The Sports

Psychologist, Birmingham, 9, 1995.

KORUC, Z.; ARSAN, N.; KAGAN, S.; KOCAEKSL, S. Motivational tendencies and competitive anxiety in second league football teams. Journal of Sports Science and Medicine, Eastern Mediterenean University, Cyprus v.6, n.10, p.154155, 2007.

\section{LIPP, M. E. N. (Org.) . Mecanismos}

Neuropsicofisiológicos do Stress: teoria e aplicações clínicas. 1. ed. São Paulo: Casa do Psicólogo, 2003.

MALINA, R. M.; WOYNAROWSKA, B.; BIELICKI, T.; BEUNEN, G.; EWELD, D.; GEITHNER, C. A.; HUANG, Y. C.; ROGERS, D. M. Prospective and retrospective longitudinal studies of the growth, maturation, and fitness of Polish youth active in sport. International Journal of Sports Medicine, Stuttgart, v.18, n.3, p.179-85, 1997.

MALINA, R.M.; PENA REYES, M.E.; EISENMANN, J.C.; HORTA, L.; RODRIGUES, J.; MILLER, R. Height, mass and skeletal maturity of elite Portuguese soccer players aged 11-16 years. Journal of Sports Science, London, v.18, p.68593, 2000.

MALINA, R. M.; BOUCHARD, C. Atividade Física do atleta jovem: do crescimento à maturação. São Paulo: Ed.Roca, 2002.

MARGIS, R; et al. Relação entre estressores, estresse e ansiedade. Revista de. Psiquiatria do Rio Grande do Sul. Porto Alegre, v.25, 2003.

MARQUES, M. P; SAMULSKI, D. M. Analise da carreira esportiva de jovens atletas de futebol na transicao da fase amadora para a fase profissional: escolaridade, iniciacao, contexto socio-familiar e planejamento da carreira. Revista Brasileira de Educacao Fisica e Esporte, São Paulo, v. 23, n. 2, p. 103-19, 2009.

MATSUDO, V. K. R.; MATSUDO, S. M. M. Avaliação e prescrição da atividade física na criança. Revista da Associação dos Professores de Educação Física de Londrina, Londrina, v.10, n.17, p.46-55, 1995.

MAZZUCO, M. A. Relação entre maturação e variáveis antropométricas, fisiológicas e motoras em atletas de futebol de 12 a 16 anos. Dissertação de mestrado. Universidade Federal do Paraná, 2007.

MIRWALD R. L.; BAXTER-JONES, A. D. G.; BAILEY, D. A.; BEUNEN, G. P. An assessment of maturity from anthropometric measurements.
Medicine \& Sciense of Sports \& Exercise, Madison, v.34, n.4, p.689-694, 2002.

NIDEFFER, R. M. Entrenamiento para el control de la atencion y la concentración. In: Williams, J. M. Psicologia aplicada al deporte. Madrid, Biblioteca Nueva, p. 373-91, 1991.

OLIVEIRA, P. R.; AMORIM, C. E. N.; GOULART, L. F. Estudo do esforço físico no futebol junior. Revista Paranaense de Educação Física, Maringa, v.1, n.2, p.49-58, 2000.

OMMUNDSEN, Y.; ROBERTS, G. C.; et al. Parental and coach support or pressure on psychosocial outcomes of pediatric athletes in soccer. Clinical Journal of Sport Medicine, Oslo, Norway v.16, n.6, p.522-6, 2006.

PAIN, M. A.; HARWOOD, C. The performance environment of the England youth soccer teams. Journal of Sports Sciense, Loughborough, UK, v.25, n.12, p.1307-1324, 2007.

PENA REYES, M. E.; CARDENAS-BARAHONA, E.; MALINA, R. M. Growth, physique, and skeletal maturation of soccer players 7-17 years of age. Auxology Human Biology. Budapest, v.25, p.453-458, 1994.

ROBERGS, R. A.; ROBERTS, S. O. Exercise physiology: exercise, performance, and clinical applications. Boston, Massachusetts: WCB McGraw-Hill, 1997.

RUBIO, K. O imaginario da derrota no esporte contemporaneo. Psicologia eSociedade, São Paulo, n. 18, v. 1, p. 86-91, 2006.

SAMULSKI, D. M.; CHAGAS, M. H. Análise do stress na competição em jogadores de futebol de campo das categorias infantil e juvenil. Revista Brasileira de Ciência e Movimento, Brasília, n.4, p.12-18, 1992.

SAMULSKI, D. M.; CHAGAS, M. H. Análise do estresse psíquico na competição em jogadores de futebol de campo das categorias juvenil e júnior. Revista da Associação dos Professores de Educação Física de Londrina, Londrina, v.11, número 19, 03-1, 1996.

SAMULSKI, D. M. Psicologia do esporte: um manual para educação física, psicologia e fisioterapia. São Paulo: Manole, 2002.

SANCHES, A. B. Influência de fatores produtores de estresse em jogadores de futebol do Distrito Federal. Tese doutorado. Universidade de Brasília, 2004.

SEABRA, A.; MAIA, J. A.; GARGANTA, R. Crescimento, maturação, aptidão física, força 
explosiva e habilidades motoras específicas.

Estudo em jovens futebolistas e não-futebolistas do sexo masculino dos 12 aos 16 anos de idade.

Revista Portuguesa de Ciências do Desporto, Porto, v.1, n.2, p.22-35, 2001.

SMOLL, F.; SMITH, L. Competitive stress and young athlete. In Teitz, C.C. Scientific

Foundations of Sports Medicine. Ontário: B.C. Becker, 1989.

STEFANELLO, J. M. F. Situações de estresse no vôlei de praia de alto rendimento: um estudo de caso com uma dupla olímpica. Revista

Portuguesa de Ciência do Desporto, Porto, v.7, n.2, p.232-244, 2007.

STEINBERG, L. Adolescence. $3^{\circ}$ Ed, New York: MacGraw-Hill, 1993.

STERLEMANN, V.; GANEA, K.; et al. Long-term behavioral and neuroendocrine alterations following chronic social stress in mice: Implications for stress-related disorders.

Hormones and Behavior, 2007.

TOURINHO FILHO, H.; TOURINHO, L. S. P. R. Crianças, adolescentes e atividade física: aspectos maturacionais e funcionais. Revista Paulista de Educação Física, São Paulo, v.12, n.1, p.71-84, 1998.

VEALEY, R. Conception of sport-confidence and competitive orientation: preliminary investigation and instrument development. Journal of Sport Psychology, New York, n.8, p. 221-46, 1986.

VILLAR, R.; DENADAI, B. S. Efeitos da idade na aptidão física em meninos praticantes de futebol de 9 a 15 anos. Motriz. Revista de Educação

Física. UNESP. Rio Claro, v.7, n.2, p.93-97, 2001.

WEINBERG, R. S.; GOULD, D. Fundamentos da psicologia do esporte e do exercício. $2^{\stackrel{a}{a}}$ ed. Porto Alegre: Artmed, 2001.

WEISS, M.R.; McAULEY, E.; EBBECK, V.; WIESE, D.M. Self-esteem and causal attributions for children's psychological and social competence in sport. Journal of Sport and Exercise Psychology, Champaign, v.12,p.2136,1990 .
Recebido em: 4 de março de 2011. Aceito em: 3 de outubro de 2011.

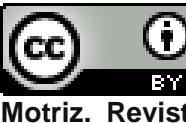

Motriz. Revista de Educação Física. UNESP, Rio Claro, SP, Brasil - elSSN: 1980-6574 - está licenciada sob Creative Commons - Atribuição 3.0

\section{Endereço:}

Priscilla Bertoldo dos Santos

Rua João Sguário, 791 Bairro CIC

Curitiba PR Brasil

81170-000

Telefone: (41) 8420-8592

e-mail: pribertoldo@gmail.com 